\title{
Population Briefs, Vol. 19, no. 1
}

Population Council

Follow this and additional works at: https://knowledgecommons.popcouncil.org/ series_newsletters_popbriefs How does access to this work benefit you? Let us know!

\section{Recommended Citation}

Population Briefs 19(1): New York: Population Council, 2013. 


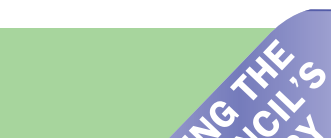

$\sin _{0}$

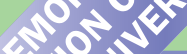

$a^{2} a^{2}$

Volume 19, Number 1

April 2013

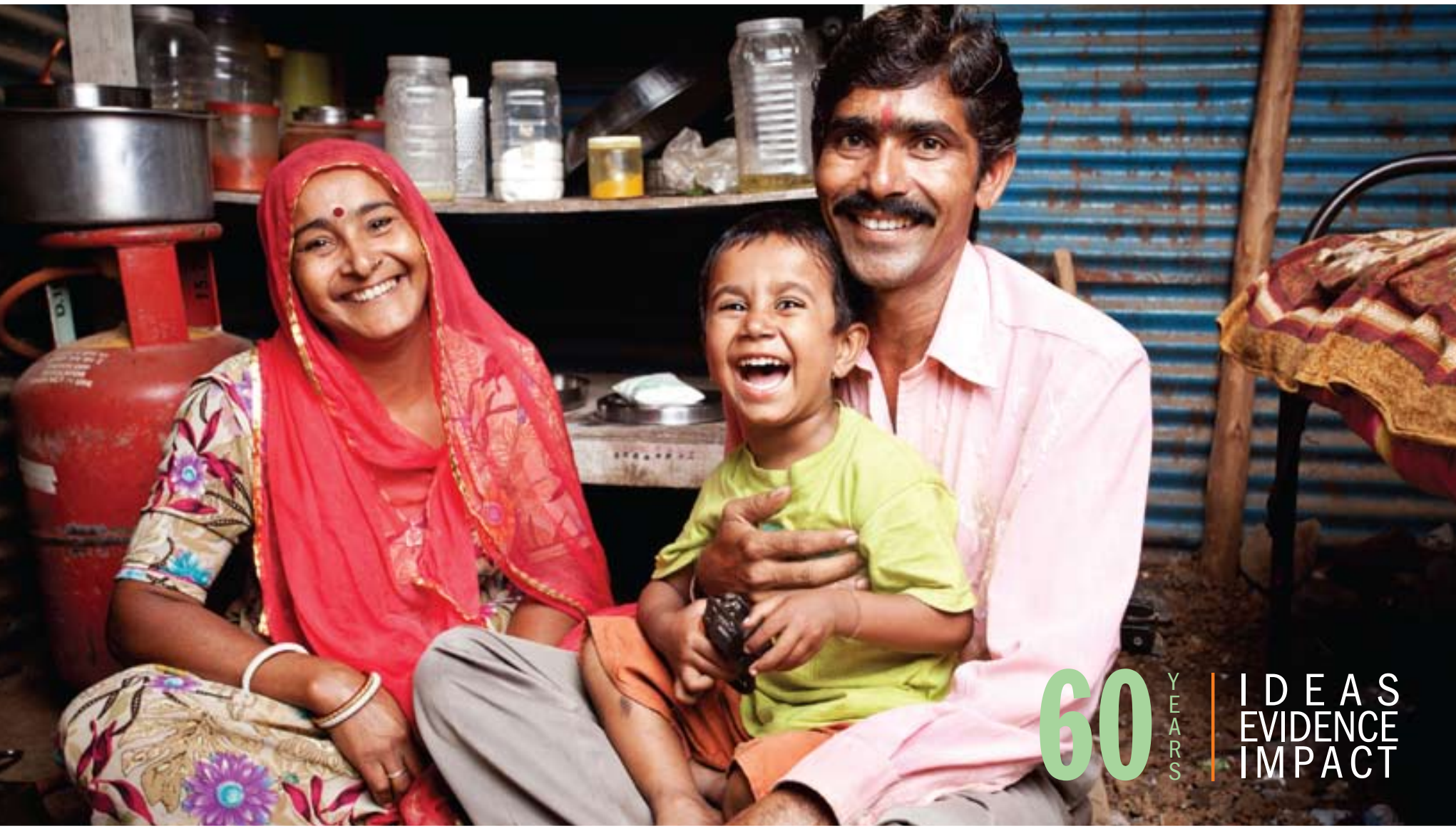

INSIDE

From the editor

Advancing Long-Acting Reversible Contraception .................................... 2

Shaping Policy and Practice: The Council's Peer-Reviewed Journals...... 4

Bringing to Light the Hazards of Smoking When Using the Pill ............... 5

Improving Quality of Care in Family Planning.......................................... 6

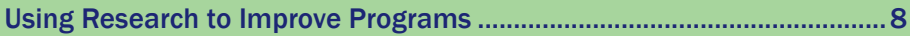

Developing Microbicides to Combat HIV Transmission ............................ 9

Broadening the Response to Population Momentum .............................10

Charting a Positive Future for Girls in Developing Countries..................12

Identifying the HIV Risk and Sexual Health Needs of

Men Who Have Sex with Men in Africa

Shaping Abortion Reform in Mexico City

Ensuring Protections for Young People in Research

Placing Equality, Respect, and Dignity at the Center of

Sexuality and HIV Education

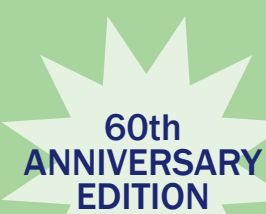

1

This special issue of

Population Briefs focuses on 60 years of groundbreaking Population Council research. 
Population Briefs is a semiannual newsletter summarizing new peer-reviewed research published by the Population Council. In celebration of the Council's $60^{\text {th }}$ anniversary, this issue takes a slightly different approach. Instead of reviewing recent research, we look back at some of the Council's most influential publications since our founding. For 60 years, the Council has been changing the way the world thinks about critical health and development issues. From creating the field of highly effective, long-acting, reversible contraception to calling the world's attention to the importance of investing in adolescent girls, the Population Council has delivered ideas, evidence, and solutions that improve lives around the world. This issue of Population Briefs illustrates our impact.

\section{As editor of Population Briefs} for the past 14 years, I've never been prouder to be a part of the Council.

I hope you enjoy this issue.
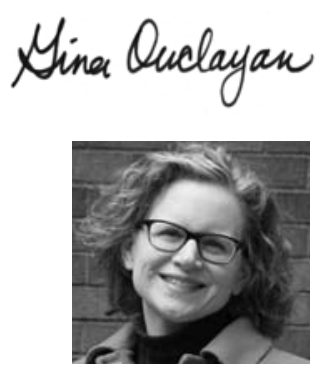

\section{Advancing Long-Acting Reversible Contraception}

The Population Council developed the copper T IUD, one of the most effective and cost-effective contraceptive methods available today.

\section{The Landscape}

The first modern IUDs were developed in the early 1900s, but had many shortcomings. Women who used them experienced pain and heavy bleeding, and the devices were often expelled from the uterus. The Population Council began contraceptive research in 1956 and was the first organization to recognize the potential of the IUD to be a better, more effective contraceptive method. The Council invested significantly in new research and product development to achieve that potential.

\section{The Paradigm Shift}

In the mid-1960s, Population Council biomedical researcher Howard Tatum determined that a common weakness of existing IUDs was the incompatibility of their shape and size with the dimensions of the uterus. Taking into account the musculature of the uterus, in 1967 Tatum produced the first "Tatum-T" plastic IUD. The

\section{"Most nongovernmental organizations claim to promote change for the better; the Population Council actually has hard evidence of having changed the lives and expectations of hundreds of millions of people."}




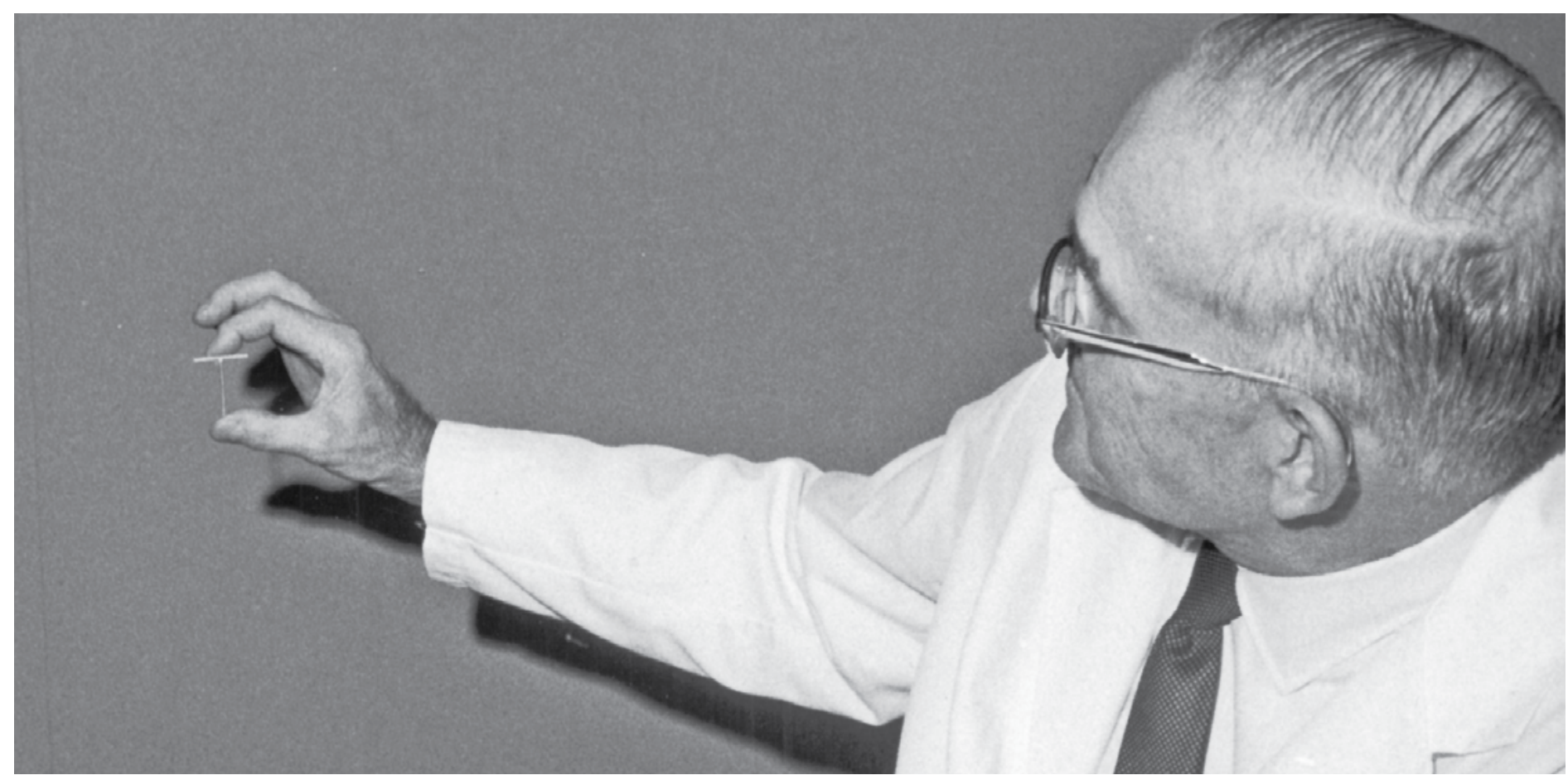

Howard Tatum displays the T-shaped intrauterine device he developed, which helped to revolutionize the technology.

Tatum-T produced only one-fifth the incidence of pain and bleeding and half the expulsions as another commonly available IUD. However, the Tatum-T was not an effective contraceptive until Tatum's colleague Jaime Zipper of the World Health Organization added copper to it, significantly improving its effectiveness.

In 1976, the U.S. Food and Drug Administration (FDA) approved the Copper T200 IUD, the first-ever New Drug Application sponsored by a nonprofit research organization. And in 1984, the FDA approved a longer-lasting Council product with more copper, the Copper T 380A IUD, now known as ParaGard ${ }^{\circledR}$. The modern copper T IUD is one of the most effective and cost-effective contraceptive methods available; it lasts 12 years and its contraceptive effect is reversed as soon as it is removed.

The Tatum-T was also used as the foundation for a hormonal IUD, developed with Council funding by a team led by University of Helsinki scientist Tapani Luukkainen, a member of the Council's International Committee for Contraception Research (ICCR). With the addition of a progestin, Luukkainen and the Council sought to decrease menstrual bleeding and prevent anemia. From this initial design evolved Mirena ${ }^{\circledR}$, a levonorgestrelreleasing intrauterine system (IUS), approved by the FDA in 2000 for contraception and later for the treatment of heavy menstrual bleeding.

\section{The Lasting Impact}

The Council is a recognized international leader in the development of safe, highly effective, reversible contraceptive methods. To date, more than 120 million women have used a Council-developed contraceptive, including ParaGard and Mirena; implants like Norplant $^{\circledR}$ and Jadelle ${ }^{\circledR}$; and Progering ${ }^{\circledR}$, the contraceptive vaginal ring for breastfeeding women. Today the Council is developing a new contraceptive vaginal ring that will be effective for one year.

The Council has worked with ministries of health, international organizations, and health care providers in many developing countries to facilitate the introduction of the Copper T 380A IUD into family planning pro- grams and to develop guidelines for safe provision of and counseling for the product. And, through partnerships with the pharmaceutical company that licenses Mirena, the IUS has been distributed at no cost to more than 65,000 low-income women in the U.S. and to around 46,000 women in developing countries.

Speaking of the Council's contraceptive development, Dr. Laragh Gollogly, then a senior editor at The Lancet, wrote, "Most nongovernmental organizations claim to promote change for the better; the Population Council actually has hard evidence of having changed the lives and expectations of hundreds of millions of people."

\section{SOURCES}

Tatum, Howard J. 1972. "Intrauterine contraception," American Journal of Obstetrics and Gynecology 112(7): 1000-1023.

Nilsson, C.G., E.D.B. Johansson, and T. Luukkainen. 1976. "A D-norgestrel-releasing IUD," Contraception 13(4): 503-514

\section{FUNDING}

Ford Foundation and Swedish Medical Research Council 


\section{Shaping Policy and Practice: The Council's Peer-Reviewed Journals}

\section{The Landscape}

John D. Rockefeller 3rd founded the Population Council in 1952 to study the relationship between population and human welfare. It was a bold endeavor: at the time, interest in the field of population studies was just beginning to emerge.

Rockefeller's goal was to generate policyrelevant knowledge and programs to help improve the lives of the world's most vulnerable people. During its first decades, the Council helped define the population field through high-quality research and programs and the publication of two scholarly journals: Studies in Family Planning and Population and Development Review. The journals continue to stimulate debate and disseminate knowledge that helps shape the field.

\section{The Influence}

\section{Studies in Family Planning}

The Council published the first issue of Studies in 1963. It included the results of groundbreaking research like the family planning program in Singur, India — considered to be the first effort to lower birth rates through edu-

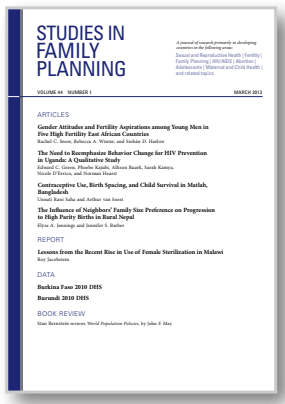

cation — and a review of a government-funded program to promote pre-pregnancy health and family planning in Taichung, Taiwan.

Articles have presented conceptual, analytical, and methodological insights that have changed the way family planning and sexual and reproductive health services are provided. For example, a 1977 article, "Mortality risk associated with the use of oral contraceptives," by Anrudh K. Jain, illuminated a critical link between smoking and poor health among users of the Pill and shaped FDA recommendations. And a 1990 article, "Fundamental elements

\section{"I have found great inspiration from Population and}

Development Review. We should be grateful for the many ways this collaborative project has moved the world of demography forward."

- economist Nancy Folbre, University of Massachusetts, Amberst

of the quality of care: A simple framework," by Judith Bruce, led directly to improvements in reproductive health care delivery around the world. Today, the journal includes articles, reviews, and commentaries on relevant topics like fertility trends, HIV and AIDS, timing of pregnancy, and intimate-partner violence.

\section{Population and Development Review}

Population and Development Review (PDR) was founded by noted demographer Paul Demeny in 1975 to advance knowledge of the relationships between population processes and socioeconomic change, and to provide a forum for discussion of related issues of public policy. Since its inception, the journal's content has spanned a broad range of disciplines, covered theoretical advances and empirical analyses, and reported on both historical and contemporary policy challenges.

Influential articles have included, in 1978, "A framework for analyzing the proximate determinants of fertility," by John Bongaarts, which set out the factors that directly influence fertility and presented a simple model for calculating their effects. The model has been incorporated in hundreds of research studies to collect and report data used by policymakers and program managers. "Routes to low mortality in poor countries," by John Caldwell, published in 1986, demonstrated the powerful role of women's education in improving health outcomes. For policymakers, it pointed to the possibilities for achieving health breakthroughs even at low levels of economic development.

Nineteen book-length supplements to the journal have provided perspectives on topics such as population and environment; aging, health, and public policy; and consequences of demographic transition. Population and Public Policy: Essays in Honor of Paul Demeny, published in 2013 , is the latest of these, containing 21 essays by leading social scientists on some of today's most important population and development issues.

\section{The Lasting Impact}

Studies in Family Planning and Population and Development Review are prominent journals that undergo a rigorous peer-review article-selection process, ensuring the quality of their widely cited articles. Both publications are read by development experts, social scientists, policymakers, policy analysts, and researchers. The insights disseminated in Studies and PDR have shaped understanding of critical issues in global development and helped transform programs and policies around the world.

FUNDING

Anonymous and United Nations Population Fund 


\section{Bringing to Light the Hazards of Smoking When Using the Pill}

In 1977, Population Council researcher Anrudh K. Jain illuminated the increased risk of death for women who smoke heavily and use oral contraceptives.

\section{The Landscape}

Before Jain's analysis, it was thought that use of oral contraceptives greatly increased the risk of heart attack, stroke, and death among women over 40. The FDA had proposed guidance to physicians that "the use of oral contraceptives in women in this age group [40 and over] is not recommended."

\section{The Paradigm Shift}

Contrary to current thinking, Jain's work revealed that the Pill was safe for most women of any age - and that the factor that posed a considerable health risk was heavy smoking.

Jain reviewed several studies from Great Britain and the United States and examined annual mortality rates from heart attacks among women, both those who used and did not use the Pill, those who smoked and those who did not, and those from various age groups.

Jain found that "the annual mortality rate among women ages 40-44 who use oral contraceptives but do not smoke is 10.7 per 100,000, while the rate among pill users who smoke is about 62 per 100,000." The rate for women in this age group who neither took the Pill nor smoked was 7.4 per 100,000. He found that for nonsmokers ages 30-44, there was no statistical difference in death rates between those who used the Pill and those who did not. His findings shifted the discussion from age as a major risk factor for women on the Pill to the risks of smoking for Pill users.

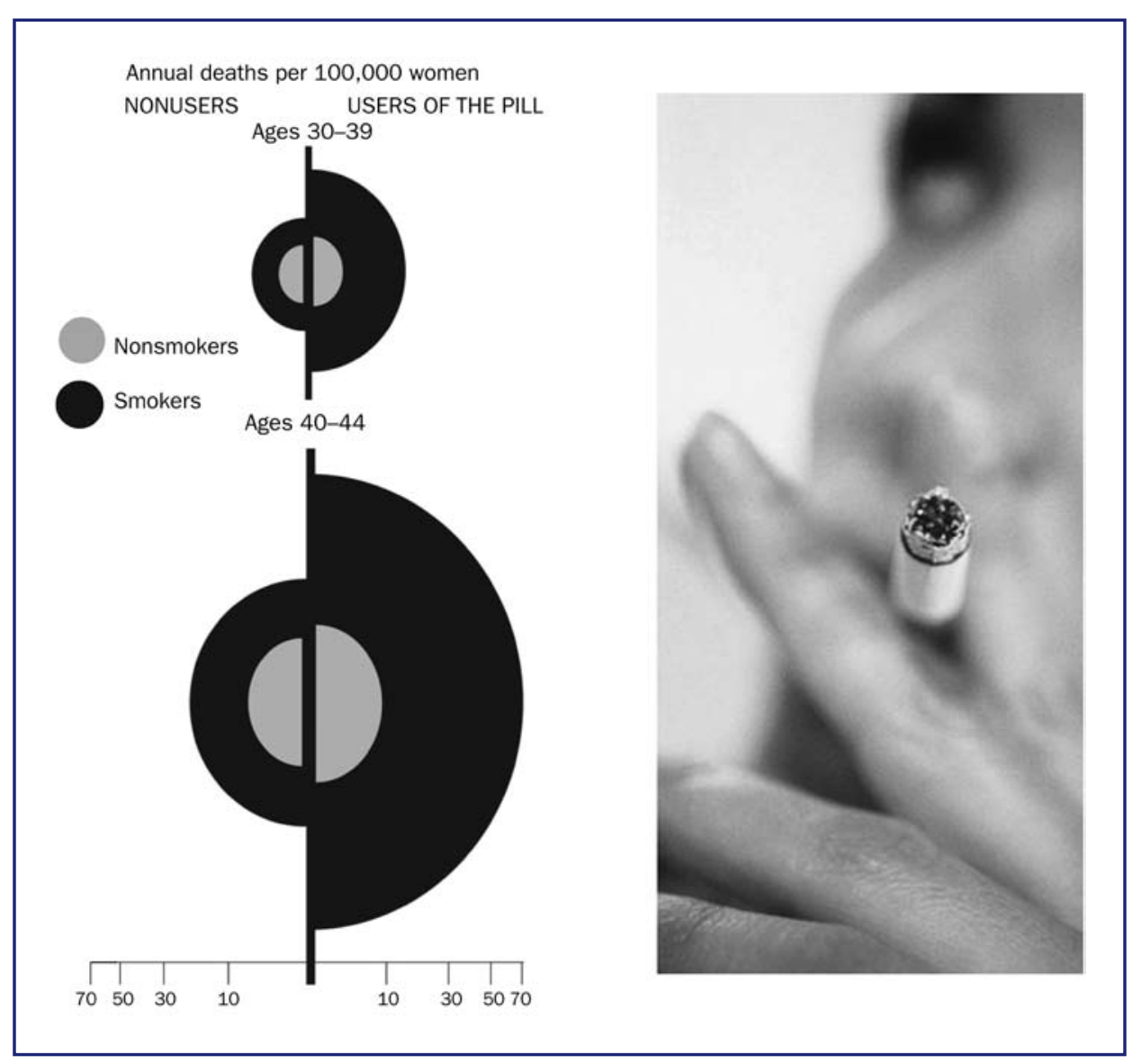

An analysis by Population Council researcher Anrudh K. Jain showed that for women taking the Pill smoking greatly increases health risks. Jain is now a Distinguished Scholar at the Council.

\section{The Lasting Impact}

Jain's analysis changed the way the Pill was viewed by women, doctors, and researchers. He described the extent to which smoking raises the risks for those on the Pill, and demonstrated that the Pill is safe for most non-smoking women of any age.

As a result of Jain's work, the FDA altered its recommendations to advise physicians about the health risks of smoking and Pill use. Today, oral contraceptives are widely recognized as safe for most women who do not smoke.

\section{SOURCES}

Jain, Anrudh K. 1976. "Cigarette smoking, use of oral contraceptives, and myocardial infarction," American Journal of Obstetrics and Gynecology 126(3): 301-307.

Jain, Anrudh K. 1977. "Mortality risk associated with the use of oral contraceptives," Studies in Family Planning 8(3): 50-54.

\section{FUNDING}

US National Institutes of Health 


\section{Improving Quality of Care in Family Planning}

Population Council researcher Anrudh K. Jain provided some of the first empirical evidence for the relationship between family planning method choice as an aspect of service quality and the prevalence of contraceptive use. Since then, several studies have demonstrated that improving the quality of reproductive health services increases contraceptive use.

\section{The Landscape}

Population Council policy analyst Judith Bruce expanded upon Jain's observations. Bruce maintained that family planning is a vital social investment and an essential aspect of development, independent of a country's demographic interests. She also contended that when the quality of family planning services is improved, more women would become committed and satisfied users, with clear demographic benefits. These outcomes would include a healthier and more empowered female population. Improving the quality of family planning services would also help a country meet its distinct but important goal of slowing population growth.

To make these good intentions a programmatic reality, Bruce developed the family planning quality of care framework, which motivated widespread reassessment of how family planning services could be improved.

\section{The Paradigm Shift}

Bruce detailed six "salient elements of family planning programs that together constitute quality":

1. Choice of methods: "Choice is not only the first, but the fundamental element of providing quality in services," wrote Bruce. Clients' needs and preferences change over time; having the ability to switch methods when women desire is a foundation for satisfied and sustained use of family planning. The spectrum of methods offered must have sufficient diversity to meet the varying needs of clients.

2. Information given to clients: "There persists poor knowledge of the proper use, risks, and benefits of contraceptives," wrote Bruce. Providers often do not inquire about clients' intentions and health and fail to offer information necessary to help users select and practice contraception effectively.

\section{Technical competence: "Clients bear} the consequences of poor technique in the form of unnecessary pain, infection, other serious side effects, and in some circumstances, death," Bruce wrote.

4. Interpersonal relations: It is often assumed that providers can't be taught better interpersonal relations. However, they can, Bruce maintained. And, "for many clients," Bruce wrote, "being treated badly is worse than receiving no care at all." Providers must recognize and address all of the personal dimensions of service, including sensitivity and respect.
"For many clients, being

treated badly is worse than

receiving no care at all."

-Judith Bruce, Population

Council policy analyst

\section{Mechanisms to encourage continu-}

ity of care: The broad objective of encouraging continuity of care is to ensure that after the first contact with a family planning provider, the trail does not end. "Effective follow-up and support of clients may demand some new resources," wrote Bruce, "but they also require a stronger marketing sense and innovative thinking."

\section{Appropriate constellation of services:} Programs can go beyond the conventional boundaries of family planning to offer reproductive health services as well as the diagnosis and treatment of reproductive

\section{Quality issues to be addressed in family planning programs}

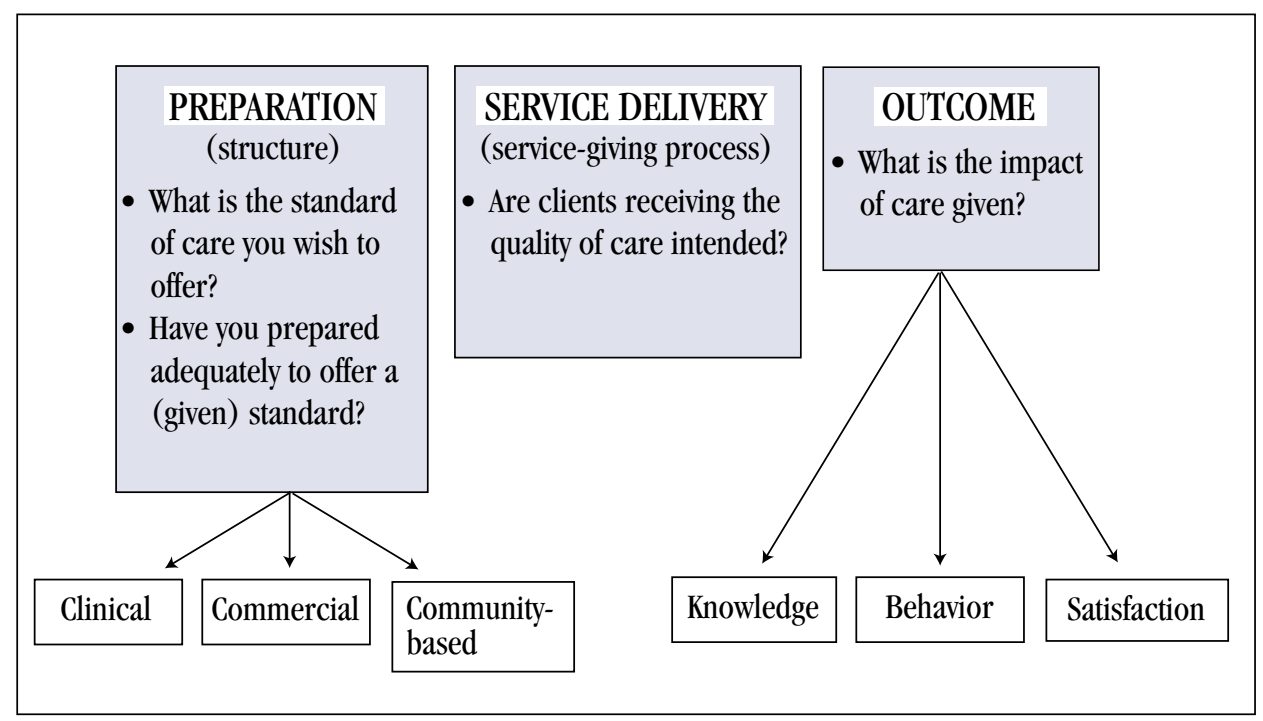


tract infections and sexually transmitted infections, among other services. "The appropriate constellation of services is one that responds to clients' rhythms and health concepts," Bruce wrote, "rather than inflexible medical demarcations of where a need begins and where it ends."

The Council has developed and refined strategies-including situation analysis, operations research, and the HARI ("helping achieve reproductive intentions") index- to measure and improve quality of care. In seeking to enhance program quality, the Council urged program managers to ask and answer four key questions:

1. What standard of care does the program wish to offer?

2. What standard of care is the program able to offer?
3. What quality of care is actually offered to and received by clients?

4. What effects do services have on clients' health and wellbeing?

This assessment tool has paved the way for national program managers to expand and improve their services and eliminate practices that fail to protect and promote the health and wellbeing of individuals.

\section{The Lasting Impact}

For more than two decades Bruce's Quality of Care Framework has guided the design and delivery of services in the fields of family planning and reproductive health. The framework has been modified over the years, with components added or broadened depending on the context and scope of a program, yet it remains the foundation for defining the goals and evaluating the outcomes of family planning programs.

\section{SOURCES}

Miller, Robert, Andrew Fisher, Kate Miller, Lewis Ndhlovu, Baker Ndugga Maggwa, Ian Askew, Diouratie Sanogo, and Placide Tapsoba. 1997. The Situation Analysis Approach to Assessing Family Planning and Reproductive Health Services: A Handbook. New York: Population Council.

Bruce, Judith. 1990. "Fundamental elements of the quality of care: A simple framework," Studies in Family Planning 21(2): 61-91.

Jain, Anrudh K. 1989. "Fertility reduction and the quality of family planning services," Studies in Family Planning 20(1): 1-16.

Kumar, Sushil, Anrudh K. Jain, and Judith Bruce. 1989. "Assessing the quality of family planning services in developing countries." Programs Division Working Paper (no. 2). New York: Population Council.

\section{FUNDING}

United States Agency for International Development

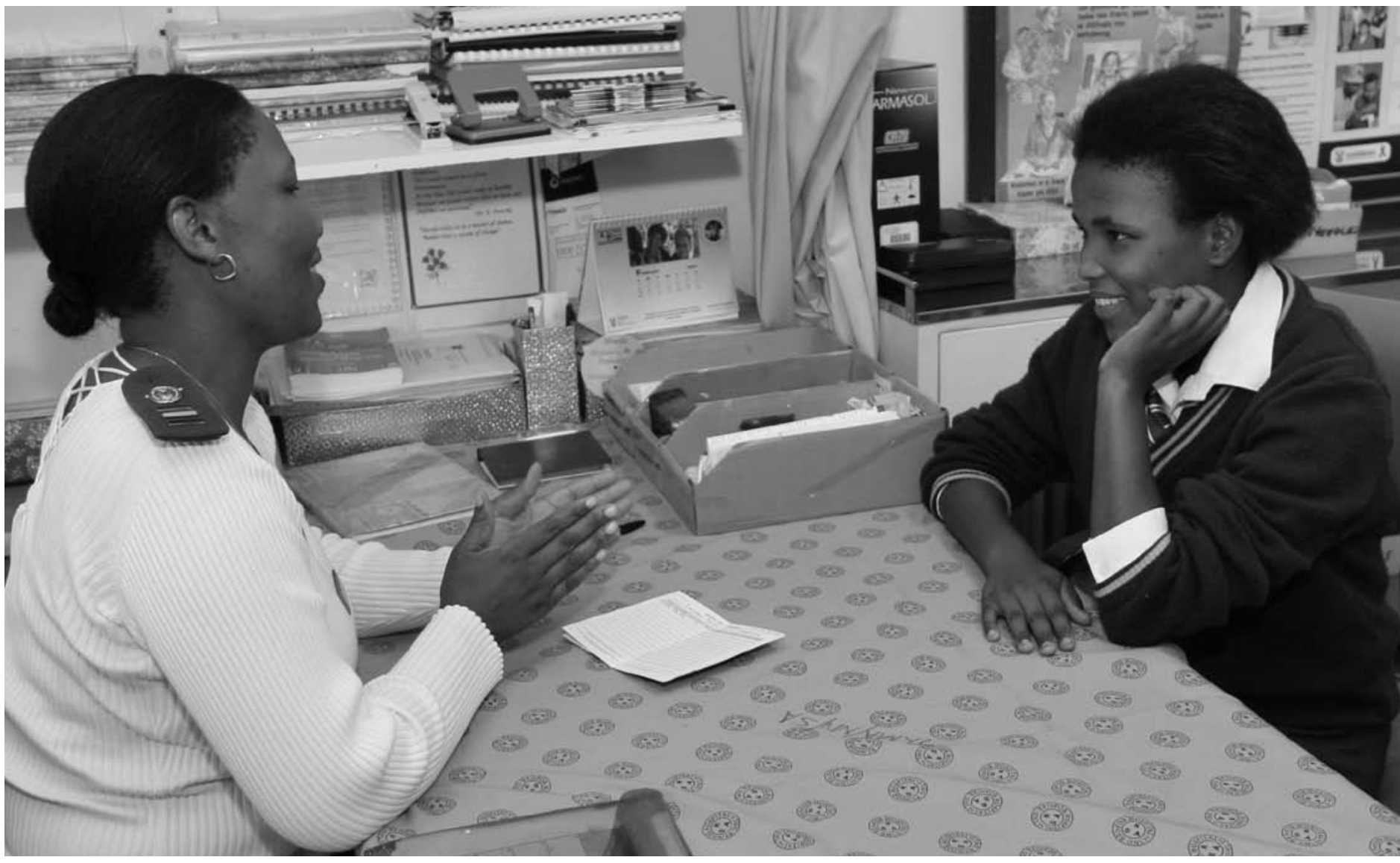

Judith Bruce's Quality Care Framework has guided the design and delivery of family planning and reproductive health services for more than two decades. 


\section{Using Research to Improve Programs}

\section{The Landscape}

Global health programs, such as those to improve access to family planning services or reduce transmission of HIV, can succeed or fail for a variety of reasons. Some factors, such as civil unrest or monsoon rains, are beyond a program manager's control. Managers have the ability to change other factors, however, such as staff training and supply logistics. But before the 1980s, there was no standard, evidence-based process to help program managers improve systems by identifying servicedelivery problems and testing solutions.

\section{The Paradigm Shift}

The Population Council took an existing strategy — known as operations research — and refined it for use in the field of family planning and reproductive health. The method takes a step-by-step approach to addressing planning, training, and evaluation issues that are under a manager's control. In 1983, Council researchers Andrew Fisher, John Laing, John Stoeckel, and John Townsend published the Handbook for Family Planning Operations Research Design, making it accessible to family planning program managers around the world.

Operations research uses five basic steps to examine and improve the day-to-day activities of a program:

- Identifying and diagnosing problems

- Selecting strategies to address identified problems

- Testing and evaluating those strategies

- Disseminating findings

- Using findings to improve or expand programs

\section{The Lasting Impact}

A groundbreaking Council operations research project in Latin America - Investigación Operativa para América Latina (INOPAL) -

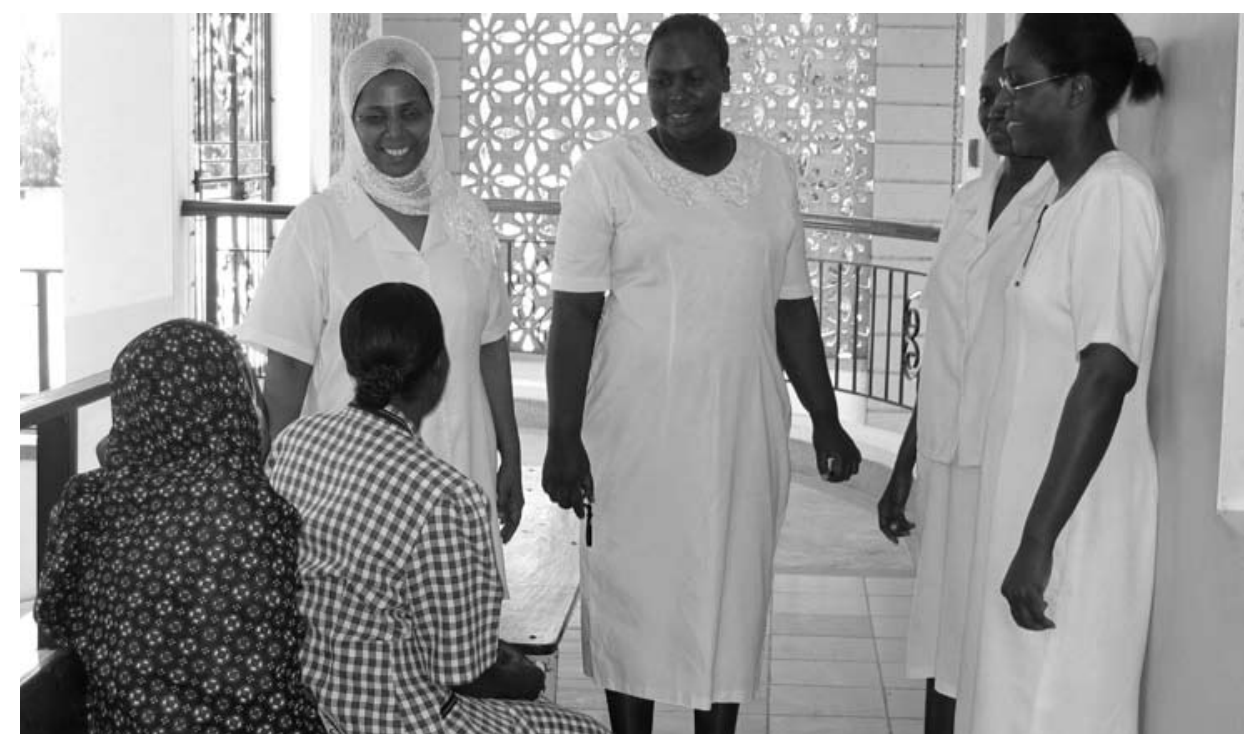

Nurses speak with two patients at the Mkomani BOMU clinic in Mombasa, Kenya, a study site that examined the impact of antiretroviral therapy on sexual behavior.

sought to improve the availability and costeffectiveness of family planning and maternal and child health services in more than a dozen Latin American countries. INOPAL worked with clinics, policymakers, and civil society to dramatically improve the quality of care provided to Latin American women. Thanks to its success, Mexico extended family planning services to all hospitals and health centers country-wide, and went on to provide INOPALbased training in reproductive health services in seven other Latin American countries. The Council later led the global, decade-long Frontiers in Reproductive Health program of operations research to improve services.

In 1997, the Council began its decadelong Horizons Program to improve the field of HIV prevention, treatment, and care. Horizons was among the first programs to conduct operations research on services that provide antiretroviral medication in developing countries. Studies in Kenya and Zambia led to the expansion of services to prevent mother-to-child HIV transmission in both countries. On the basis of their experience with HIV programs, Council operations research experts Andrew A. Fisher and James R. Foreit published Designing HIV/
AIDS Intervention Studies: An Operations Research Handbook in 2002.

The Council has completed more than 300 operations research projects around the world and published two indispensable guides for program managers on how to implement operations research to improve services. The handbooks have strengthened research capacity, providing expert guidance so that program managers in developing countries can improve programs and shape global health policies.

\section{SOURCES}

Fisher, Andrew A. and James R. Foreit with John Laing, John Stoeckel, and John Townsend. 2002. Designing HIVIAIDS Intervention Studies: An Operations Research Handbook. Washington, DC: Population Council.

Fisher, Andrew A., John Laing, John Stoeckel, and John Townsend. 1991. Handbook for Family Planning Operations Research Design. Second Edition. New York: Population Council.

Rivero-Fuentes, Estela, et al. 2008. Assessing Integration Methodology (AIM): A Handbook for Measuring and Assessing the Integration of Family Planning and Other Reproductive Health Services. FRONTIERS Manual. Washington, DC: Population Council.

\section{FUNDING}

United States Agency for International Development 


\section{Developing Microbicides to Combat HIV Transmission}

\section{The Landscape}

In the 1980s, at the beginning of the HIV epidemic, AIDS was thought to be primarily a "gay male" disease, and many people wrongly believed that women were not at risk. But just ten years later, the number of infections among women was as high as that among men in subSaharan Africa, where HIV was predominantly transmitted through heterosexual sex.

Prevention efforts at the time focused on abstinence or monogamy, treatment for sexually transmitted infections (STIs), and condom use. But for many women, social, cultural, and economic inequalities severely limited their ability to protect themselves from infection.

\section{The Paradigm Shift}

Recognizing the prevention challenges women faced, the international community began calling for a woman-controlled HIV prevention method that would provide protection without partner negotiation. At the time, published scientific research described the need for and the biology behind microbicides, female-initiated methods for reducing male-to-female transmission of HIV during sexual intercourse. But beyond the lab, none took a far-reaching look at the possible challenges of developing an acceptable, accessible, effective, and safe microbicide.

In 1992, the Population Council coorganized one of the first international symposiums on microbicides, bringing together women's health advocates, scientists, and program planners to explore the complexities of microbicide development from conceptualization to market. The outcome of that meeting was a seminal paper written by Council researcher Christopher J. Elias and Lori Heise of the Center for Women's Global Leadership, which pulled together current knowledge about the need for microbicides and scrutinized challenges - including issues regarding basic biology, clinical trials, and programs—-for future microbicides development.

"[The paper] simultaneously catalyzed action within the Council and the broader scientific community, and amongst women's health advocates," wrote sociologist Susan E. Bell in her essay, "Sexual synthetics: Women, science, and microbicides."

Building on the concepts advanced in the paper, the Council and the International Women's Health Coalition formed the Women's Health Advocates on Microbicides (WHAM). As a potential microbicide was pursued in the Council's lab, WHAM held consultations and conducted studies to investigate what type of formulation women would find acceptable and want to use, how to conduct an ethical clinical trial, and how best to obtain informed consent. These studies informed not only the Council's work, but that of other product developers.

\section{The Lasting Impact}

The Population Council has been at the forefront of microbicide development for more than three decades. The Elias-Heise working paper provided strategic direction for the field of microbicide development, which now has doz-

\section{The paper "simultaneously}

catalyzed action within the

Council and the broader

scientific community, and

amongst women's health

advocates."

-sociologist Susan E. Bell

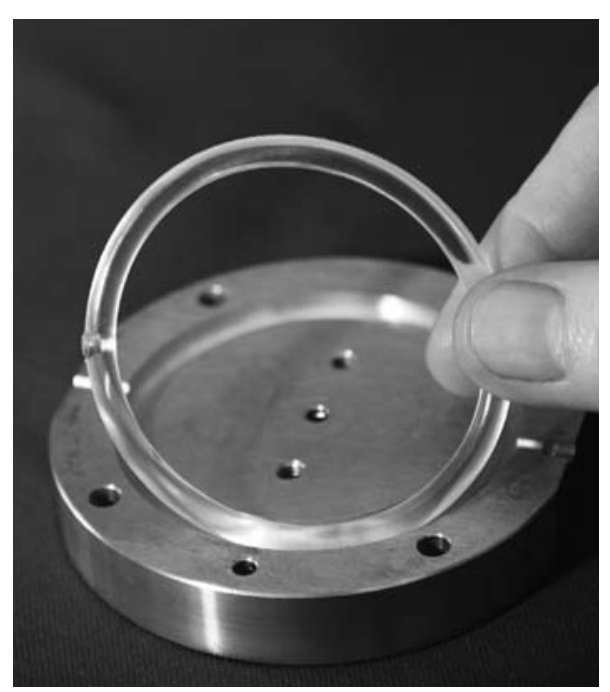

In 2012, the Population Council provided the first efficacy data on the delivery of a microbicide from a vaginal ring. The findings indicate strong potential for success of such rings in women.

ens of products undergoing clinical testing and in various phases of development. The Council is advancing new agents and formulations as potential microbicide options for women, all of which are designed to prevent at least one STI in addition to HIV. Some also include a contraceptive. The Council is also defining regulatory pathways for the introduction of multipurpose prevention technologies with the goal of streamlining the approval processes for new and complex products.

\section{SOURCE}

Elias, Christopher J. and Lori Heise. 1993. "The development of microbicides: A new method of HIV prevention for women," Programs Division Working Paper no. 6. New York: Population Council.

\section{FUNDING}

Ford Foundation, John D. and Catherine T. MacArthur Foundation, and the Rockefeller Foundation 


\section{Broadening the Response to Population Momentum}

Until the mid-1990s, policymakers took a single approach to addressing population growth: increasing access to family planning. But in early 1994, Population Council demographer John Bongaarts published a ground-breaking analysis, "Population policy options in the developing world," in the journal Science. The article advocated a significantly expanded approach, particularly investing in the lives of adolescent girls, to advance public health and wellbeing while slowing the pace of population growth.

\section{The Landscape}

In 1994, the population of the developing world stood at 4.5 billion. The governments of many developing countries had adopted policies, particularly family planning programs, to reduce population growth. Family planning services provided information about and access to contraception to allow couples to choose when to have children and how many. The programs contributed to a sharp rise in the percentage of couples using contraception, from 10 percent in the mid-1960s to 50 percent in 1990; concurrently a significant decline occurred in the average number of children born per woman, from 6.1 to 3.8 .

Despite these noteworthy changes in reproductive behavior, population growth continued apace, with the population of Africa alone predicted to nearly quintuple, from 0.6 billion in 1990 to 2.8 billion in 2100. Many analysts found it hard to understand why massive growth would continue despite declining fertility rates. The analysis that Bongaarts published in 1994 explained why. The growth was a by-product of the fact that the largest generation of adolescents in history was entering their childbearing years. A large cohort of young people generates "population momentum." That is, even if all young women have only two children, they will produce more than enough births to maintain significant growth over decades. Bongaarts showed that popula-

\author{
"Because it clarified the future sources of growth at a time \\ when population policies were being reconsidered on a \\ global scale, Bongaarts' article is one of the most influential \\ ever written in demography."
}

-Samuel Preston, Patrick Heuveline, and Michel Guillot in

Demography: Measuring and Modeling Population Processes tion momentum was the biggest contributor to population growth.

\section{The Paradigm Shift}

Bongaarts also offered several recommendations. First, while family planning services had achieved much, their quality and reach needed to be increased. Many women who wanted to avoid or delay pregnancy were not using a modern method of contraception. Services needed to be fully voluntary, reach more women and couples, and offer a wider choice of methods.

Second, to attenuate population momentum, Bongaarts recommended taking steps to increase the age at which a young woman has her first child. The way to do this, he contended, was by raising levels of education and postponing marriage for girls. "The longer

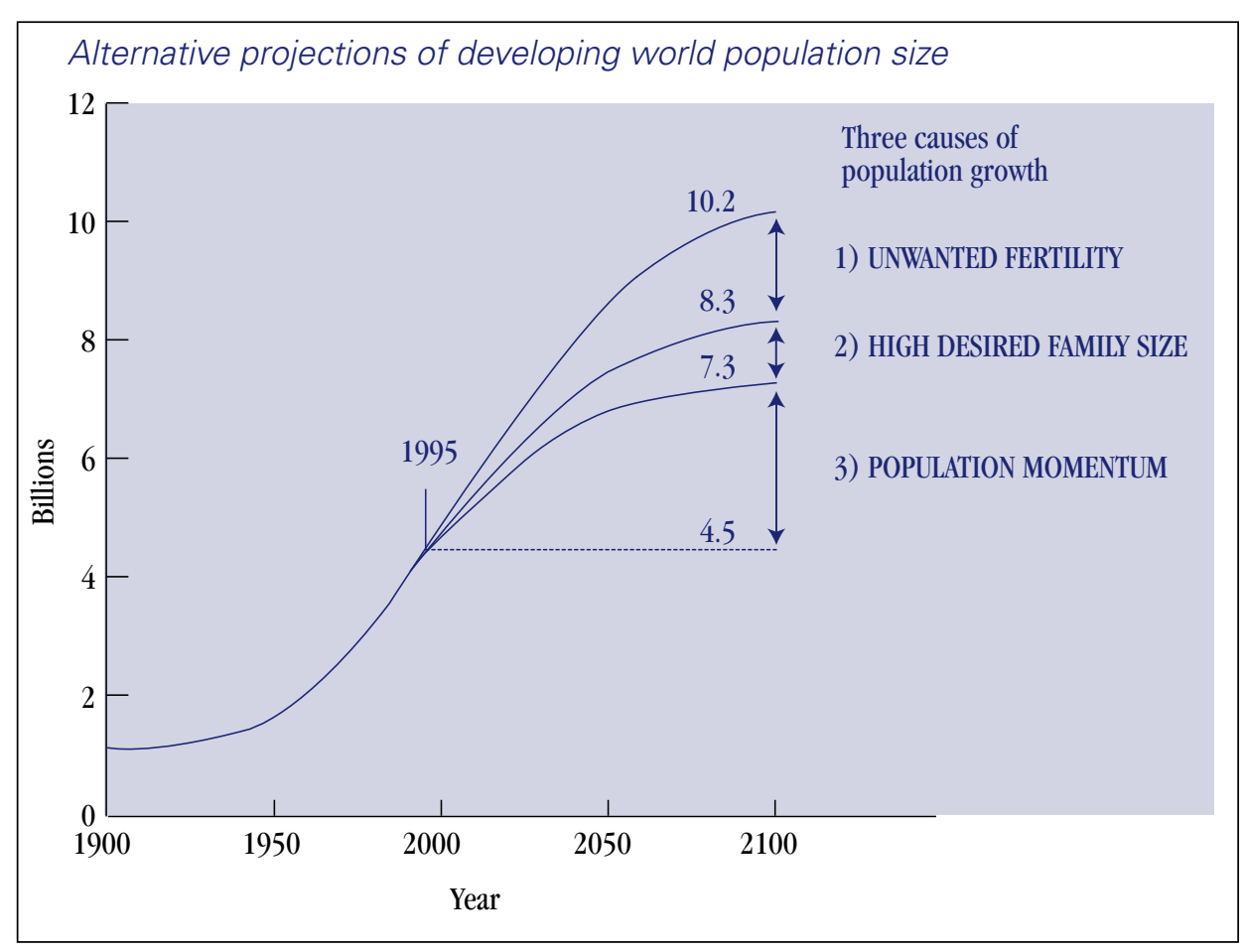

SOURCE: Bongaarts 1994. 
girls stay in school, the later they marry and the greater the delay in childbearing," he wrote. Another means of reducing population momentum is to inform people about the benefits of birth spacing, increasing the number of months between births. Along with slowing the birth rate and dampening population momentum, birth spacing improves health outcomes for mothers and babies.

Finally, Bongaarts espoused promoting and extending favorable conditions for small families. He argued that more needed to be done to improve child health and survival. This would allow people to feel confident that their children will survive to adulthood, and that they did not need to have more children than they wanted. And improving the economic, social, and legal status of girls and women would allow them to earn wages outside the home, boosting family income and quality of life and reducing poverty.

\section{The Lasting Impact}

Bongaarts's insights allowed specialists to make better decisions about how to invest effectively in programs and policies to lower population growth. His subsequent meetings with world leaders contributed to a significant global refocusing of resources on improving the lives of girls and women. This refocusing was solidified the same year when policymakers from around the world gathered for the landmark International Conference on Population and Development, in Cairo, where delegates reached a consensus that the equality and empowerment of women is a global priority.
Bongaarts's insights and recommendations are featured in demography textbooks around the world. The textbook Demography: Measuring and Modeling Population Processes by Preston, Heuveline, and Guillot (2001) states that, "Because it clarified the future sources of growth at a time when population policies were being reconsidered on a global scale, Bongaarts' article is one of the most influential ever written in demography."

\section{SOURCES}

Bongaarts, John. 1994. "Population policy options in the developing world," Science 263(5148): 771-776. Bongaarts, John. 1994. "Population policy options in the developing world," Policy Research Division Working Paper no. 59. <http://www.popcouncil.org/ pdfs/wp/059.pdf>

\section{FUNDING}

The William and Flora Hewlett Foundation and the Andrew W. Mellon Foundation

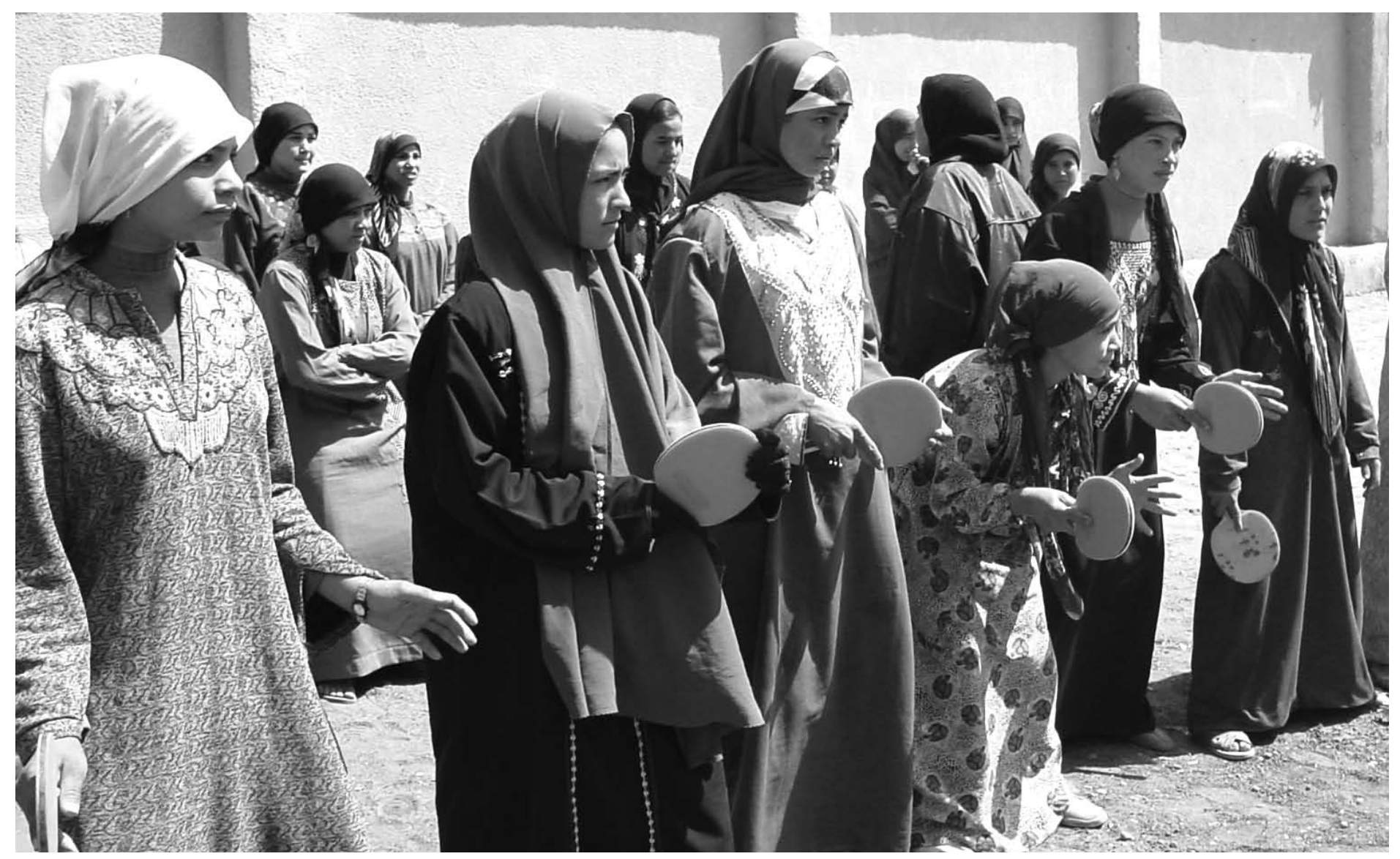

Bongaarts's recommendations, which included taking steps to raise levels of education and postpone marriage for girls, addressed population momentum. 


\section{Charting a Positive Future for Girls in Developing Countries}

\section{The Landscape}

Through the 1990s, little was known about the lives of girls in developing countries across health, social, and economic dimensions, and few policies and programs existed to support girls. Research on adolescence, defined roughly as ages 10 to 19 , focused primarily on premarital sex and pregnancy, and researchers routinely classified girls as adults once they married or gave birth, regardless of their age.

\section{The Paradigm Shift}

Population Council researchers began concentrating on the study of adolescents in the early 1990s, with the goal of bringing broader attention to social and economic issues that underpin adolescent health and wellbeing.

In 1998, the Council published The Uncharted Passage: Girls' Adolescence in the Developing World, by Council senior social

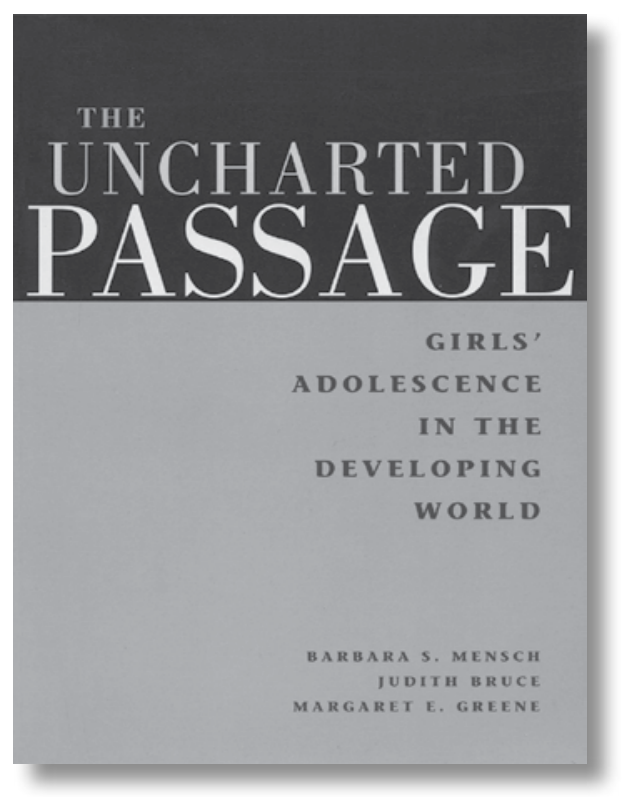

scientists Barbara S. Mensch and Judith Bruce, and Margaret E. Greene of the Center for Health and Gender Equity. The book interpreted available data on the lives of adolescent girls and argued that the second decade of life is a time of heightened vulnerability for girls and of critical capability-building for children of both sexes. "What happens between the ages of 10 and 19, whether for good or ill," wrote the authors, "shapes how girls and boys live out their lives as women and men — not only in the reproductive arena, but in the social and economic realm as well."

The available data made clear that adolescence is a time of widening opportunities for boys, but constricting opportunities for girls. Girls' school enrollment lagged behind boys', and girls spent far more time than boys on domestic chores, such as cleaning and fetching water and fuel, and far less time with friends.

The Uncharted Passage also drew attention to child marriage and its consequences. "We maintain that a girl remains a girl until she reaches age 20," wrote the authors, "no matter what occurs in her life prior to that time.... Girls' promise and vulnerability do not end when their sexual, reproductive, or married lives begin." Classifying girls who are wives or mothers as adults deprives them of rights, protections, services, and opportunities afforded to other children their age. The book outlined gaps and biases in information about girls and defined a framework for creating effective policies and programs for them.

Recognizing the Council's thought leadership on adolescence, in 2005 the National Research Council and the Institute of Medicine tapped a panel of expertsled by Cynthia B. Lloyd, then Population

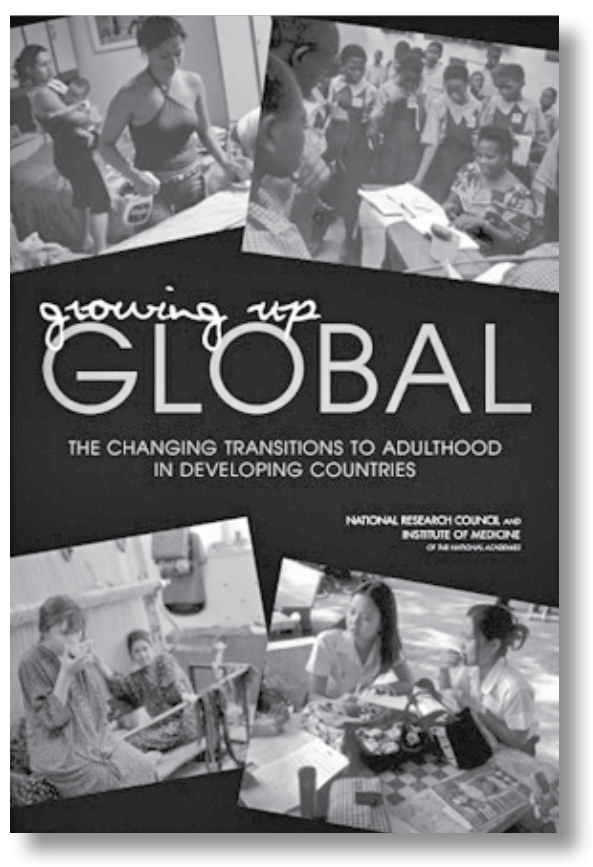

Council director of social science research, and including other Council researchers- to examine the lives of adolescents in developing countries, identifying evidence gaps, promising programs, and policy options for young people. The resulting book, Growing Up Global, provided a theoretical framework for thinking about adolescence in an era of globalization. It focused on the influence of gender and pointed to the particular educational and health disadvantages suffered by poor girls. Growing Up Global identified areas for future research, such as examining patterns of migration among young people and determining the consequences of early marriage for reproductive health and education. The years since its publication have witnessed a growing appreciation of the need for comprehensive approaches to meet the needs of young people. 


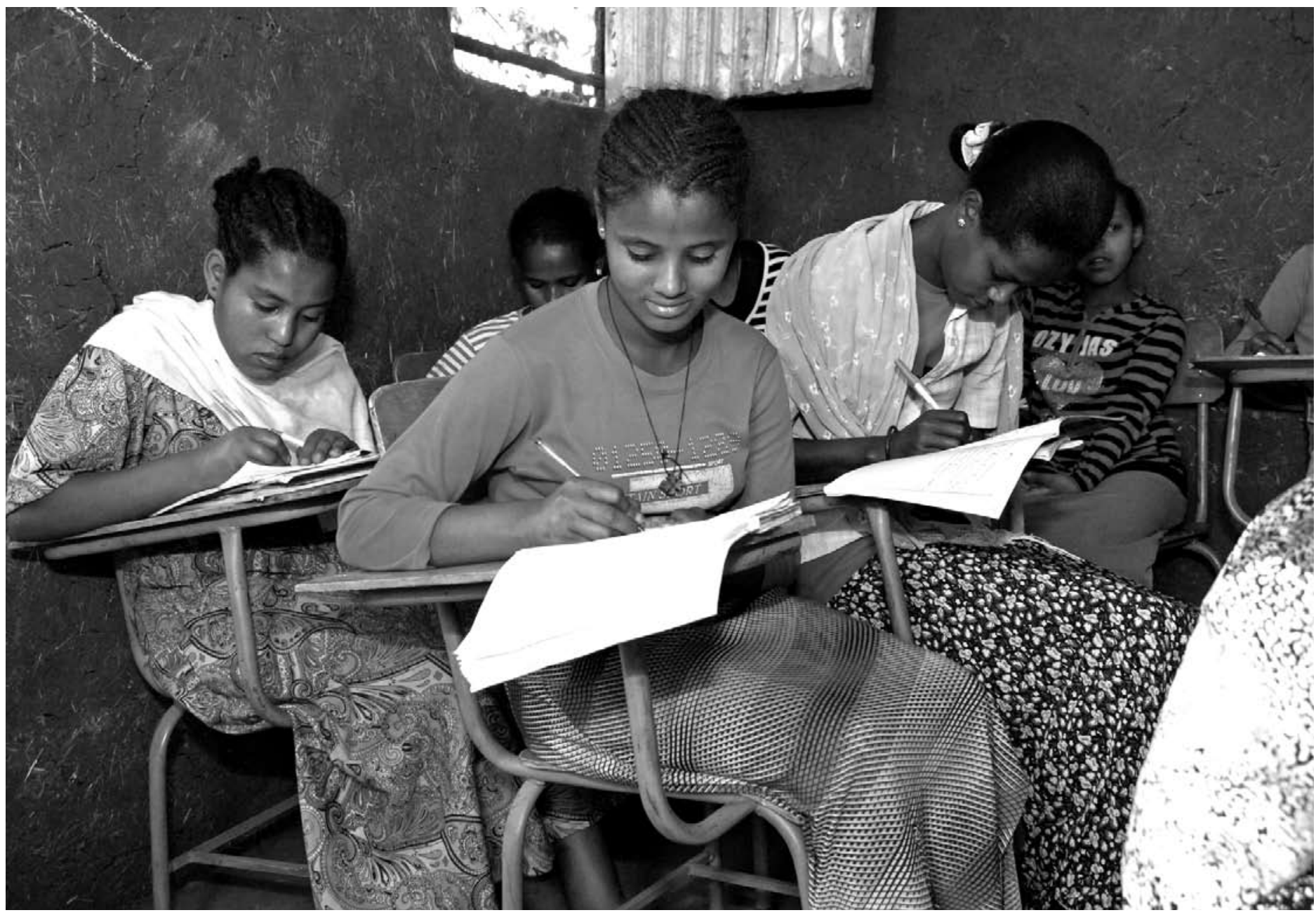

The Population Council recognized a dearth of data on the lives of adolescent girls in developing countries. The Council now has the world's largest body of research and programs for these girls.

\section{The Lasting Impact}

These publications and related Council leadership on the topic of adolescence spurred tremendous growth in attention to the needs of adolescent girls in developing countries and a recognition of the benefits of addressing their vulnerabilities. Council guidance has shaped the formation and approach of multiple organizations and coalitions - including The Girl Effect, the Coalition for Adolescent Girls, and GirlHub-aimed at addressing girls' needs and ending child marriage. Early marriage is now a priority area for the
United Nations Population Fund (UNFPA), which in 2012 pledged $\$ 20$ million to reach the most vulnerable girls at risk of early marriage. Growing Up Global set the stage for the World Bank's adolescent Girls' Initiative.

Today, the Population Council has the world's largest body of rigorous research on programs to improve the lives of adolescent girls. The Council is currently testing ways to improve the lives of girls in Bangladesh, Burkina Faso, Ethiopia, Guatemala, India, Kenya, Senegal, Tanzania, Uganda, and Zambia.

\section{SOURCES}

Mensch, Barbara S., Judith Bruce, and Margaret E. Greene. 1998. The Uncharted Passage: Girls' Adolescence in the Developing World. New York: Population Council.

Lloyd, Cynthia B. (ed.). 2005. Growing Up Global: The Changing Transitions to Adulthood in Developing Countries, a report of the National Research Council Panel on Transitions to Adulthood in Developing Countries. Washington, DC: National Academies Press.

\section{FUNDING}

The William and Flora Hewlett Foundation, The John D. and Catherine T. MacArthur Foundation, Andrew W. MelIon Foundation, National Academy of Sciences, David and Lucile Packard Foundation, United States Agency for International Development, and The World Bank 


\section{Identifying the HIV Risk and Sexual Health Needs of Men Who Have Sex with Men in Africa}

\section{The Landscape}

In developed countries, it has long been recognized that men who have sex with men (MSM) are at high risk for HIV and other sexually transmitted infections (STIs). However, in Africa, the stigma associated with homosexual behavior — and the fact that it is illegal in some countries-have kept the health needs of MSM largely hidden. As a result, health systems have lacked vital information for creating effective programs and policies that meet the health needs of this at-risk population.

\section{The Paradigm Shift}

The Population Council designed, conducted, and published the first large-scale descriptive study of African MSM, with the goal of generating research to influence policy and program change.

To reach this hidden population, the Council used a recruitment strategy called snowball sampling, in which participants randomly recruit peers from their personal networks. With this strategy, the Council documented sizable populations of MSM in Dakar, Senegal, and Nairobi, Kenya, and gave voice to their health and HIV prevention needs. Researchers also conducted in-depth interviews with service providers and with people such as masseurs, hairdressers, bartenders, and taxi drivers whose jobs put them in routine contact with MSM.

Among MSM in Kenya, Population Council research documented high levels of sex with multiple partners: 79 percent of respondents reported having two or more partners within the past year. While 75 percent reported using a condom at last anal sex with a male partner, 84 percent reported the use of oil-based lubricants, which can cause condom breakage. In Dakar, only 14 percent of MSM reported condom use at last receptive sex.

Study participants were frequent victims of stigma, discrimination, and verbal, physi$\mathrm{cal}$, and sexual violence. In Dakar, 43 percent of respondents reported being raped at least once, and 13 percent reported being raped by a police officer. Sex workers in Kenya were significantly more likely than other MSM to report an incident of discrimination (59 per- cent vs. 29 percent) and violence (39 percent vs. 19 percent). Victims of violence were also significantly less likely than other MSM to have used a condom the last time they had receptive anal sex.

Research in both Kenya and Senegal also revealed that many MSM avoid seeking health care — even when experiencing symptoms - for fear of exposing their sexual behaviors. And while many health care providers interviewed were aware that MSM seek

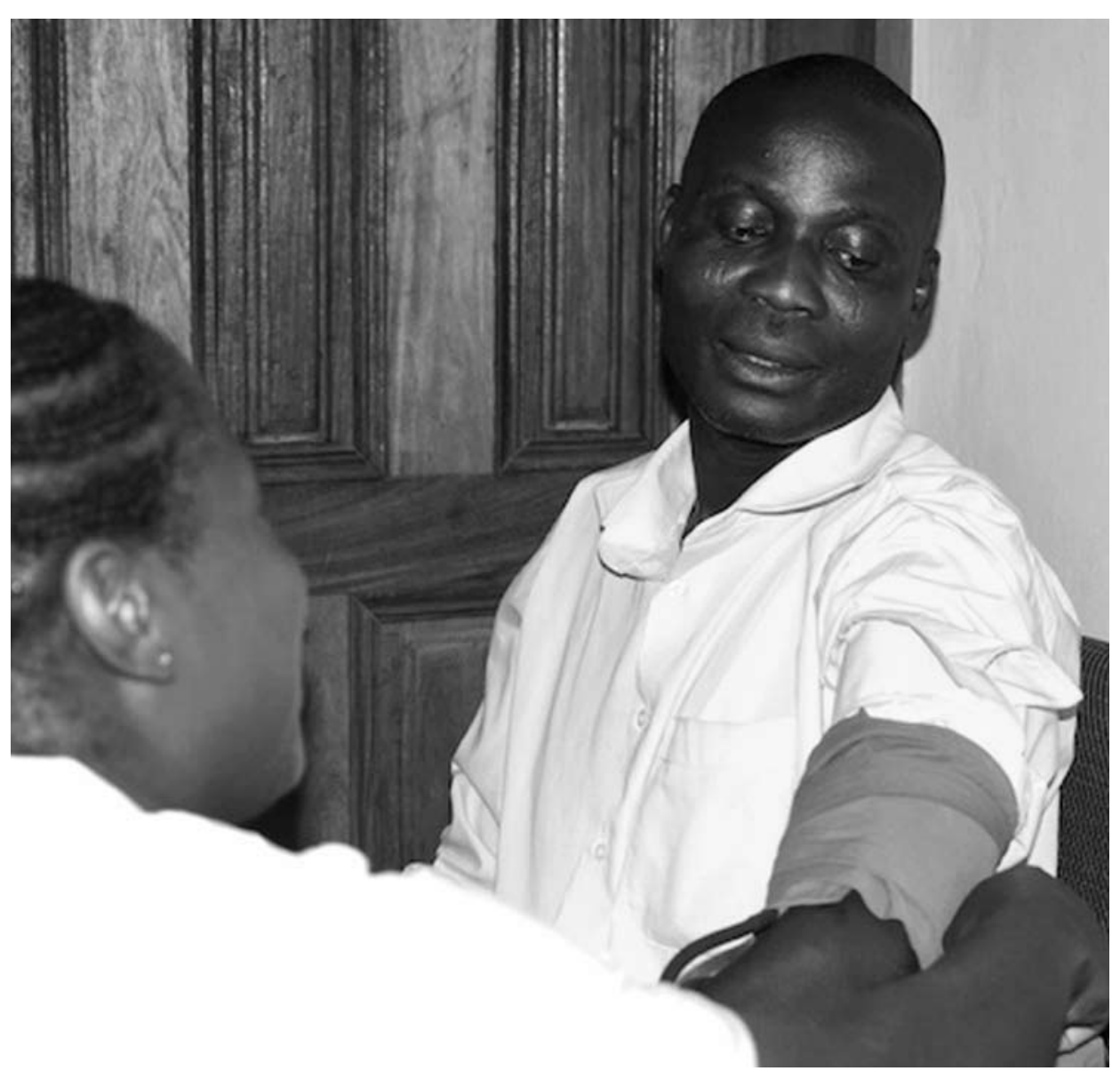

The Population Council has implemented the Men's Health Network, Nigeria, the first national, comprehensive HIV/STI prevention initiative involving men who have sex with men and other high-risk men. 


\title{
The Population Council was "the first international
}

\section{NGO to recognize that the HIV-related}

\section{vulnerabilities of men who have sex with men in}

\section{Africa deserved serious attention."}

\author{
- The International Gay and Lesbian Human Rights \\ Commission in Off the Map: How HIV/AIDS Programming \\ Is Failing Same-Sex Practicing People in Africa.
}

treatment at their facilities, they preferred not to discuss treatment and counseling issues with such men.

\section{The Lasting Impact}

Before the Council's research, MSM populations were unrecognized by government agencies in Kenya and Senegal.

These studies provided valuable data on the existence, sexual behavior, and health-seeking practices of MSM and demonstrated that research on MSM can be conducted despite such obstacles as widespread stigmatization and illegality of MSM behavior.

Findings from Kenya helped prompt the National AIDS Control Council to include MSM in national HIV policy, and informed the development and implementation of HIV programs for MSM in Kenya and elsewhere in sub-Saharan Africa. In its book, Off the Map: How HIV/AIDS Programming Is Failing Same-Sex Practicing People in Africa, the International Gay and Lesbian Human Rights Commission called the Council "the first international NGO to recognize that the HIV-related vulnerabilities of men who have sex with men in Africa deserved serious attention."

More than a decade has passed since the Senegal study; and research, policies, and services addressing the HIV-related needs of MSM are on the rise in sub-Saharan Africa. The Council's recent contributions have included support for national HIV assessments of MSM in Nigeria and Zambia, and the implementation of the Men's Health Network, Nigeria, the first national, comprehensive HIV/STI prevention initiative involving MSM and other high-risk men.

\section{SOURCES}

Niang, Cheikh Ibrahima, Moustapha Diagne, Youssoupha Niang, Amadou Mody Moreau, Dominique Gomis, Mayé Diouf, Karim Seck, Abdoulaye Sidibé Wade, Placide Tapsoba, and Chris Castle. 2002. Meeting the Sexual Health Needs of Men Who Have Sex With Men in Senegal. Horizons Final Report. Washington, D.C. Population Council.

Onyango-Ouma, W., Harriet Birungi, and Scott Geibel. 2005. Understanding the HIVISTI Risks and Prevention Needs of Men Who Have Sex with Men in Nairobi, Kenya, Horizons Final Report. Washington, D.C.: Population Council.

Geibel, Scott, Elisabeth M. van der Elst, Nzioki King'ola, Stanley Luchters, Alun Davies, Esther M. Getambu, Norbert Peshu, Susan M. Graham R.Scott McClelland, and Eduard J. Sanders. 2007. "'Are you on the market?': A capturerecapture enumeration of men who sell sex to men in and around Mombasa, Kenya," AIDS 21(10): 1349-1354

\section{FUNDING}

President's Emergency Plan for AIDS Relief through the U.S. Agency for International Development

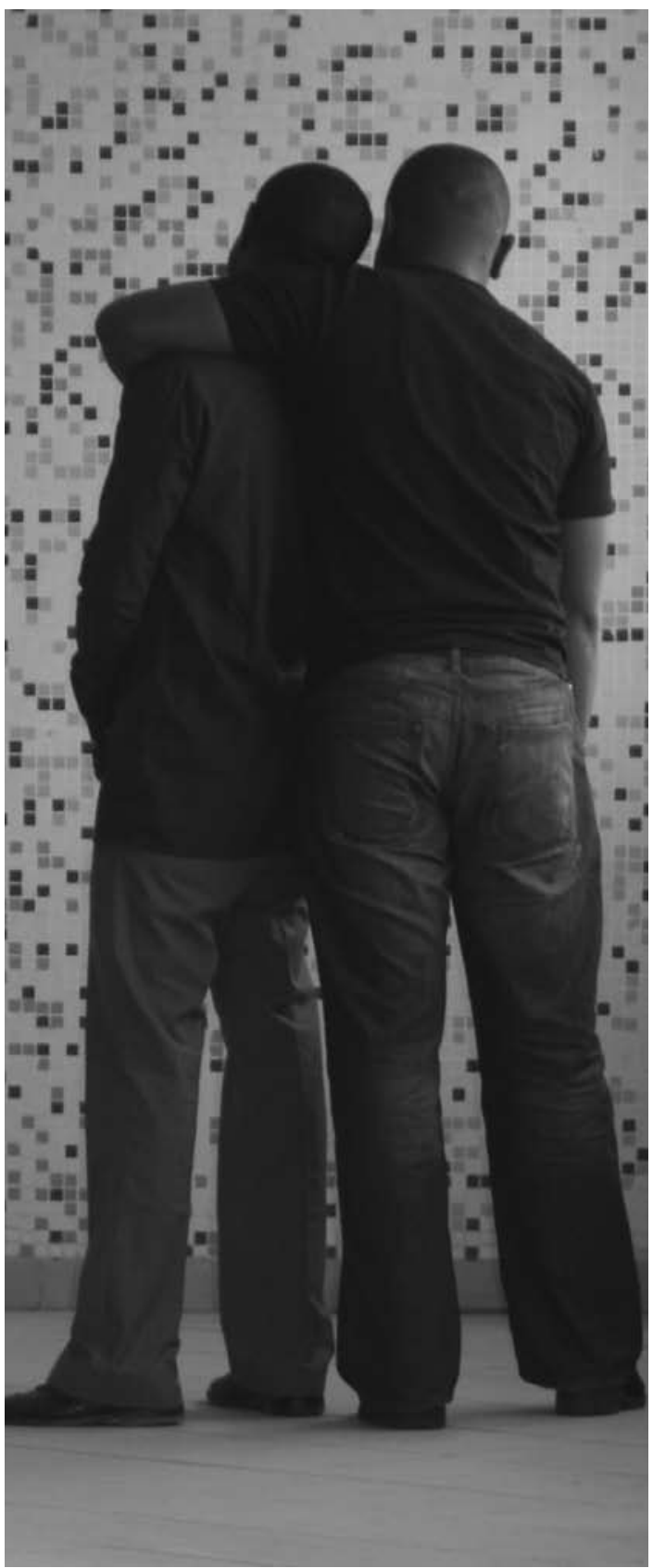

Research in both Kenya and Senegal revealed that many men who have sex with men avoid seeking health care-even when experiencing symptoms-for fear of exposing their sexual behaviors. And many health care providers prefer not to discuss treatment and counseling issues with such men. 


\section{Shaping Abortion Reform in Mexico City}

Research undertaken by the Population Council in Mexico played an important part in the passage of the landmark 2007 reform to decriminalize early abortion in Mexico City.

\section{The Landscape}

Before 2007, all Mexican states permitted abortions in cases of rape, and nearly all permitted the procedure to save a mother's life. In practice, however, it was nearly impossible for women in these circumstances to access abortion because of rigid bureaucracy and long delays.

\section{The Paradigm Shift}

In 2000, a group of organizations came together to form the National Pro-Choice Alliance for Mexico, dedicated to changing abortion laws in Mexico to protect women's health. The Council played a key role by providing evidence about abortion access, attitudes, and incidence. Three of the most important contributions to this effort were:

\section{Opinion research}

In 2000, the Council surveyed 3,000 Mexicans aged 15-65 about their knowledge of and views

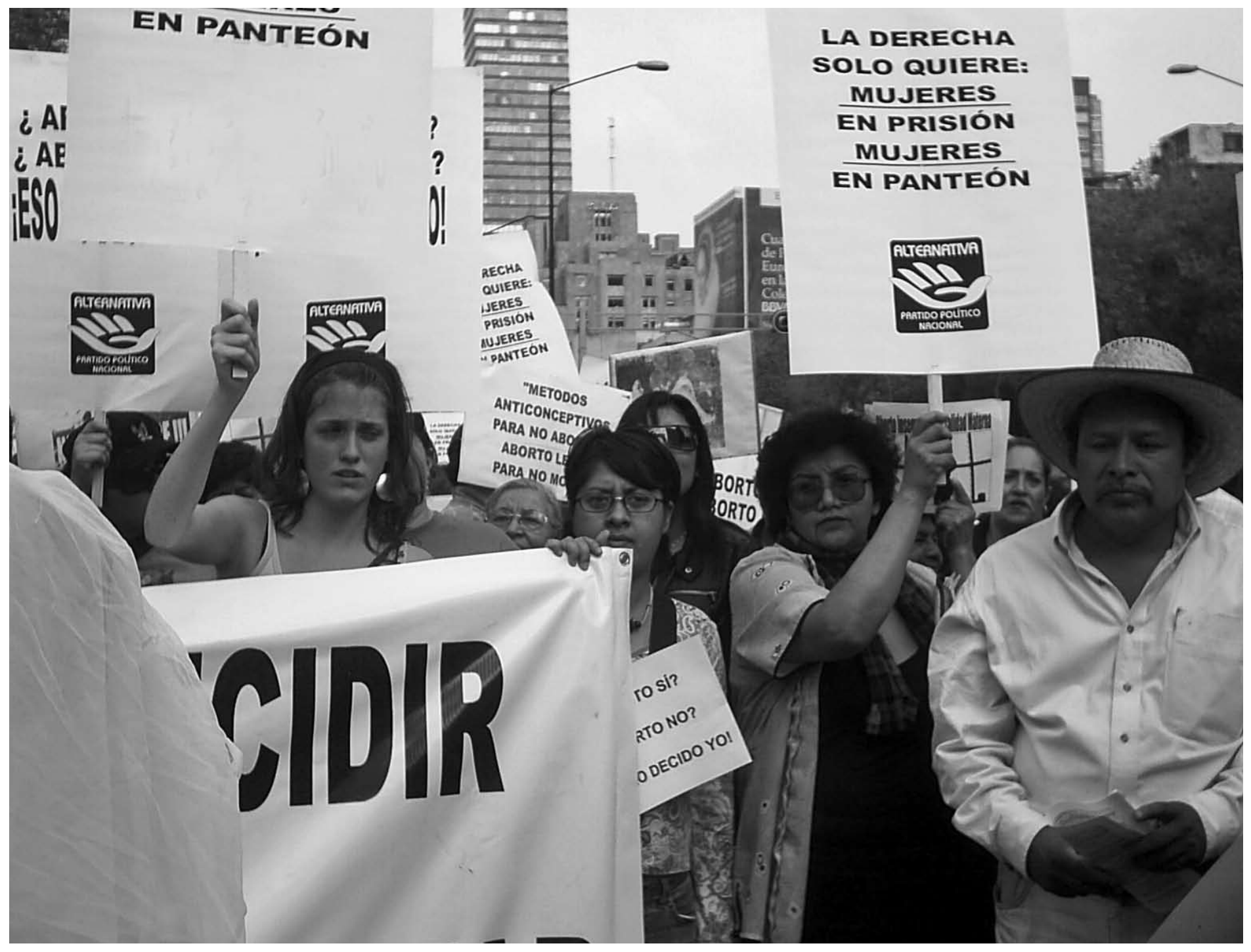

Findings from the Population Council's abortion-related research in Mexico were used by government officials and women's rights advocacy groups to shape policies to improve maternal health. 
on abortion. During a period when abortion laws throughout Mexico were severely restricted, 79 percent of people interviewed believed that abortion should be legal in certain circumstances. And while Mexico is a largely Catholic country, most Mexican Catholics did not want the Church's and legislators' beliefs to bear on abortion legislation. Instead, Catholics surveyed supported the delivery of legal abortion in public clinics.

\section{Documentation of barriers to abortion}

In 2002, Council researchers interviewed five women who became pregnant as a result of rape and documented the challenges they underwent, including lack of information about the procedure for reporting rape and an inability to obtain an abortion because of delayed access to services. These examples illustrated that even in situations where abortion was legal, access remained limited.

\section{Incidence of abortion}

The Population Council collaborated with the Guttmacher Institute to estimate the incidence of induced abortion between 1990 and 2006, before the Mexico City reform. The researchers found that in 2006, roughly 875,000 abortions were performed in Mexico: a rate of 33 per 1,000 women aged 15-44. This represented an increase of one-third from 1990 estimates (25 per 1,000). During the same period, approximately 25,000 women died from causes associated with unsafe abortion. Unsafe abortion—procedures performed by unskilled providers or under conditions that do not meet basic medical standards - are the fifth-leading cause of maternal mortality in Mexico.

The National Pro-Choice Alliance for Mexico used evidence from these and other studies to inform public officials, health providers, and the general population about the importance of increasing access to safe abortion, including the need to ease restrictions on abortion in order to safeguard women's health, reduce social stigma associated with abortion, and train health providers to offer safe and legal abortions.

\section{The Lasting Impact}

On the basis of information generated by the Population Council and others, in 2007 Mexico City's legislative assembly decriminalized abortion in the first 12 weeks of pregnancy in Mexico City. Since then, the Mexico City Ministry of Health has provided more than 90,000 free, safe, and legal early abortions to women in the capital.

"Above all, the Population Council stands for leadership and a professionalism that is

\section{"Above all, the Population Council stands for}

leadership and a professionalism that is unmatched.

\section{The Population Council is an invaluable partner in}

the Ministry's work to improve reproductive bealth in

Mexico City —always a team player, ready to lend a

hand with genuine respect."

—Leticia Bonifaz, General Counsel for Mexico City

unmatched," says Leticia Bonifaz, General Counsel for Mexico City. "The Population Council is an invaluable partner in the Ministry's work to improve reproductive health in Mexico City — always a team player, ready to lend a hand with genuine respect."

\section{SOURCES}

Garcia, S.G., C. Tatum, D. Becker, K.A. Swanson, K. Lockwood, and C. Ellertson. 2004. "Policy implications for a national public opinion study on abortion in Mexico," Reproductive Health Matters 12(24 Supplement): 65-74.

Lara, D., S. Garcia, O. Ortiz, and E.A. Yam. 2006. "Challenges accessing legal abortion after rape in Mexico City," Gaceta Médica de México, 142(suppl 2): 85-89.

Juarez, F., S. Singh, S.G. Garcia, and C. Diaz Olavarrieta. 2008." Estimates of induced abortion in Mexico: What's changed between 1990 and 2006?" International Family Planning Perspectives 34(4): 2-12.

\section{FUNDING}

Anonymous

\section{Miss an issue of Population Briefs? Printed back issues are available free of charge while supplies last.}

All electronic issues of Population Briefs are available on the Population Council's Web site: www.popcouncil.org/publications/ popbriefs/default.htm

For more information, contact:

Debra Warn, Office of Publishing and Creative Services telephone: 212-339-0514

fax: 212-755-6052

e-mail: dwarn@popcouncil.org 


\section{Ensuring Protections for Young People in Research}

\section{The Landscape}

To develop effective programs that help children and adolescents affected by HIV and AIDS, researchers, program managers, and service providers need solid data on their needs and life circumstances. Until 2003, limited guidance existed to help researchers design studies that ensured the full protection of children and adolescents involved in research.

Observing ethical standards is important for all information-gathering that involves people. However, extra precautions are needed to protect young people, who are especially vulnerable to exploitation, abuse, and other harmful outcomes. Children and adolescents have less power and access to resources than adults.

With support from the U.S. Agency for International Development (USAID), the Population Council and colleagues convened a meeting to discuss the issue. Participants included researchers and service providers with expertise in psychology, child development,

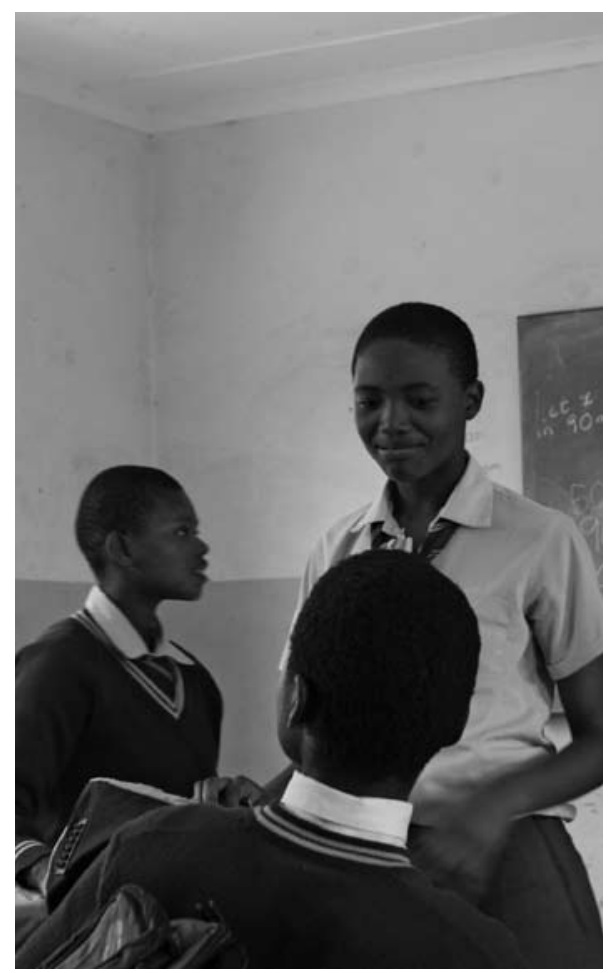

\section{"It is of paramount importance that any research has}

in place protections for young people's confidentiality, privacy, and emotional and physical well-being."

—Katie Schenk, Population Council

ethics, pediatrics, sociology, anthropology, and social work.

Participants reviewed the ethical priorities of professionals working with children affected by AIDS and other difficult circumstances, who often face poverty, stigma, or abuse. Following the meeting, Population Council researcher Katie Schenk and consultant Jan Williamson gathered insights and experiences into a groundbreaking resource for researchers working with children.

\section{The Paradigm Shift}

Schenk and Williamson's book identified challenges that confront program managers and investigators working with children and families, and proposed practical approaches to deal with them. Recognizing that methods for conducting research with adults cannot simply be transferred to young people, the book provided real-world examples and case studies that highlight the roles of interviewers, program managers, data analysts, and others in ensuring that children are protected.

The book recommended that investigators fully consider the following ethical questions in research design:

- Is the data collection activity necessary and justified?

- Is the activity designed to obtain valid information?

- Have community and stakeholder concerns been considered?
- Have adverse consequences of the activity been anticipated?

- Are procedures in place to ensure that the activity proceeds ethically?

- Is there a clear plan and adequate funding for follow-up activities?

"In this book, we tried to provide practical guidance to help program managers and researchers understand and uphold ethical standards when working with children," said Schenk. "As researchers, we know first-hand the power of evidence to improve the lives of the most vulnerable people, including children. But it is of paramount importance that any research has in place protections for young people's confidentiality, privacy, and emotional and physical well-being."

\section{The Lasting Impact}

The book is widely recognized as a seminal publication on protections for children in research. The government of South Africa, UNICEF, and the World Health Organization, among others, have used the book to formulate policy guidelines for conducting research with children.

\footnotetext{
SOURCE

Schenk, Katie and Jan Williamson. 2005. Ethical Approaches to Gathering Information from Children and Adolescents in International Settings: Guidelines and Resources. Washington, D.C.: Population Council. $<\mathrm{http}$ ://www.popcouncil.org/horizons/childrenethics. html>

FUNDING

U.S. Agency for International Development
} 


\section{Placing Equality, Respect, and Dignity at the Center of Sexuality and HIV Education}

\section{The Landscape}

Sexuality and HIV education can help adolescents develop the capacity for healthy, respectful relationships and protect themselves from unwanted and unsafe sex, unintended pregnancy, and sexually transmitted infection. "However," says Population Council social scientist Nicole Haberland, "only a few curricula actually demonstrate an effect on unintended pregnancy or on sexually transmitted infections. We see the strongest results with those curricula that emphasize gender and power issues. Unfortunately, most curricula still do not address these issues."

\section{The Paradigm Shift}

To support more effective sexuality and HIV education, the Council published It's All One Curriculum: Guidelines and Activities for a Unified Approach to Sexuality, Gender, HIV, and Human Rights Education. This resource for curriculum development was created together with six other nongovernmental organizations (NGOs) and was edited by Haberland and Council consultant Deborah Rogow. It provides a rationale, content, and sample activities for placing gender and rights at the center of sexuality and HIV curricula-both as standalone modules and integrated with topics such as relationships, puberty, and condom use.

It's All One is user-friendly and designed to be used flexibly, so that educators in diverse settings can easily understand the content and extract the level of detail they need to meet local goals. For example, educators can use this resource to help ensure that their curricula increase adolescents':

- ability to make responsible decisions and act upon their own choices;

- ability to participate in society and exercise their human rights;

- critical thinking and overall educational achievement;

- sense of control over their lives; and

- sense of sexual well-being.

"It's All One has helped the young people we work with to see that their lives are in their hands."

-Folasade Ofurune, Executive Director, Health Education and Empowerment Initiative (HEDEN), Nigeria

To reinforce the shift to this new approach, the Council provides policymakers with evidence supporting the effectiveness of this strategy and helps build educators' capacity to present this subject matter to students.

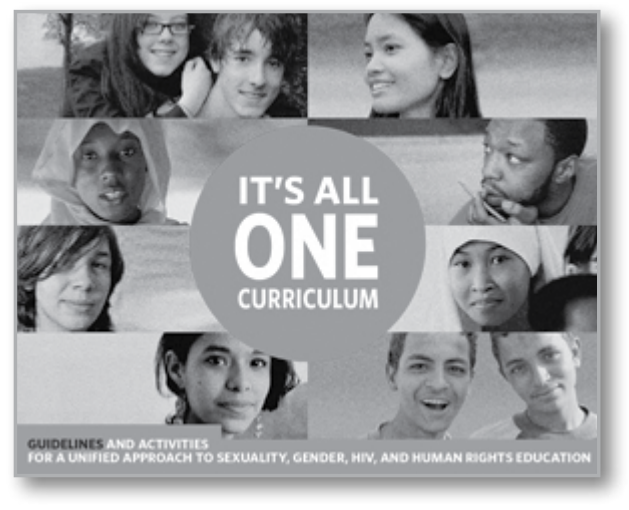

\section{The Lasting Impact}

It's All One has been in high demand since its first English publication in 2009 (a second, updated version was published in 2011). It has been translated into Spanish, French, Bangla, and Chinese, and is being adapted and translated into Arabic. Requests have come from more than 150 countries and every state in the United States - from government agencies, international NGOs, and community organizations reaching young people.

"Using It's All One has greatly improved our program performance, such that many people are now asking us to expand our activities," said Folasade Ofurune, Executive Director, Health Education and Empowerment Initiative (HEDEN), Nigeria. "In the area of critical thinking, it has helped the young people we work with to see their lives and what they do with them are in their hands."

It's All One has been used in a wide variety of settings. The broadest reach is through ministries of education and school districts in Africa, Asia, Latin America, and the United States. Several thousand community-based organizations use It's All One. For example, it is being used with rural Mayan girls in Guatemala; young people in Haiti living with HIV; girls' empowerment programs in southern Nigeria; young ethnic Tibetans in China; and members of the Mexican Scouts Association.

Educators are also using It's All One in very conservative regions: in strict Islamic settings in northern Nigeria and Aceh Province in Indonesia, in polygamous communities in Utah, and in abstinence-only schools in Nevada. Teachers in these settings report that It's All One is opening up safe ways to talk about sensitive issues like coercion, power, gender equality in relationships, and human rights.

The resource is being used in Population Council programs for adolescent girls in Bangladesh and Guatemala, and its success is being evaluated by the Council and other researchers in Bangladesh and Haiti.

\section{SOURCE}

International Sexuality and HIV Curriculum Working Group. 2009 and 2011. It's All One Curriculum: Guidelines and Activities for a Unified Approach to Sexuality, Gender, HIV, and Human Rights Education. Eds. Nicole Haberland and Deborah Rogow. New York: Population Council. <www.itsallone.org>.

\section{FUNDING}

UK Department for International Development (DFID), United Nations Population Fund (UNFPA), the Ford Foundation, the MacArthur Foundation, the Libra Foundation, and the William and Flora Hewlett Foundation 
Population Briefs is a research newsletter of the Population Council.

The Population Council confronts critical health and

development issues - from stopping the spread of HIV to improving reproductive health and ensuring that young people lead full and productive lives. Through biomedical, social science, and public health research in 50 countries, we work with our partners to deliver solutions that lead to more effective policies, programs, and technologies that improve lives around the world. Established in 1952 and headquartered in New York, the Council is a nongovernmental, nonprofit organization governed by an international board of trustees.

\section{Population Council}

Population Council, One Dag Hammarskjold Plaza, New York, New York 10017 www.popcouncil.org

Editor: Gina Duclayan

Writers: Gina Duclayan, Nicole Haberland, Sherry Hutchinson,

Kaitlin Ofman, Nicole Rajani, Katie Schenk, Annik Sorhaindo, Hannah Taboada, Nancy Termini, Christina Tse, and Deborah Weiss

Editorial Board: Sajeda Amin, Erin Kiernon, Katie D. Schenk, and Charlotte Warren

Design and Production Manager: Mike Vosika

Copyeditor: Robert Heidel

Editorial Assistant and Circulation: Debra Warn

All photos courtesy of Population Council staff except: cover photo by Vikram Raghuvanshi; p. 13 by Zeleman Productions

Population Briefs is distributed without charge. Information in this newsletter may be reproduced without permission, provided it is distributed without charge and the source is acknowledged.

To receive e-mail when a new issue of Population Briefs is posted to the Population Council Web site, register at www.popcouncil. org/signup

ISSN 1084-6786

(C) 2013 The Population Council, Inc.

Printed on recycled paper.

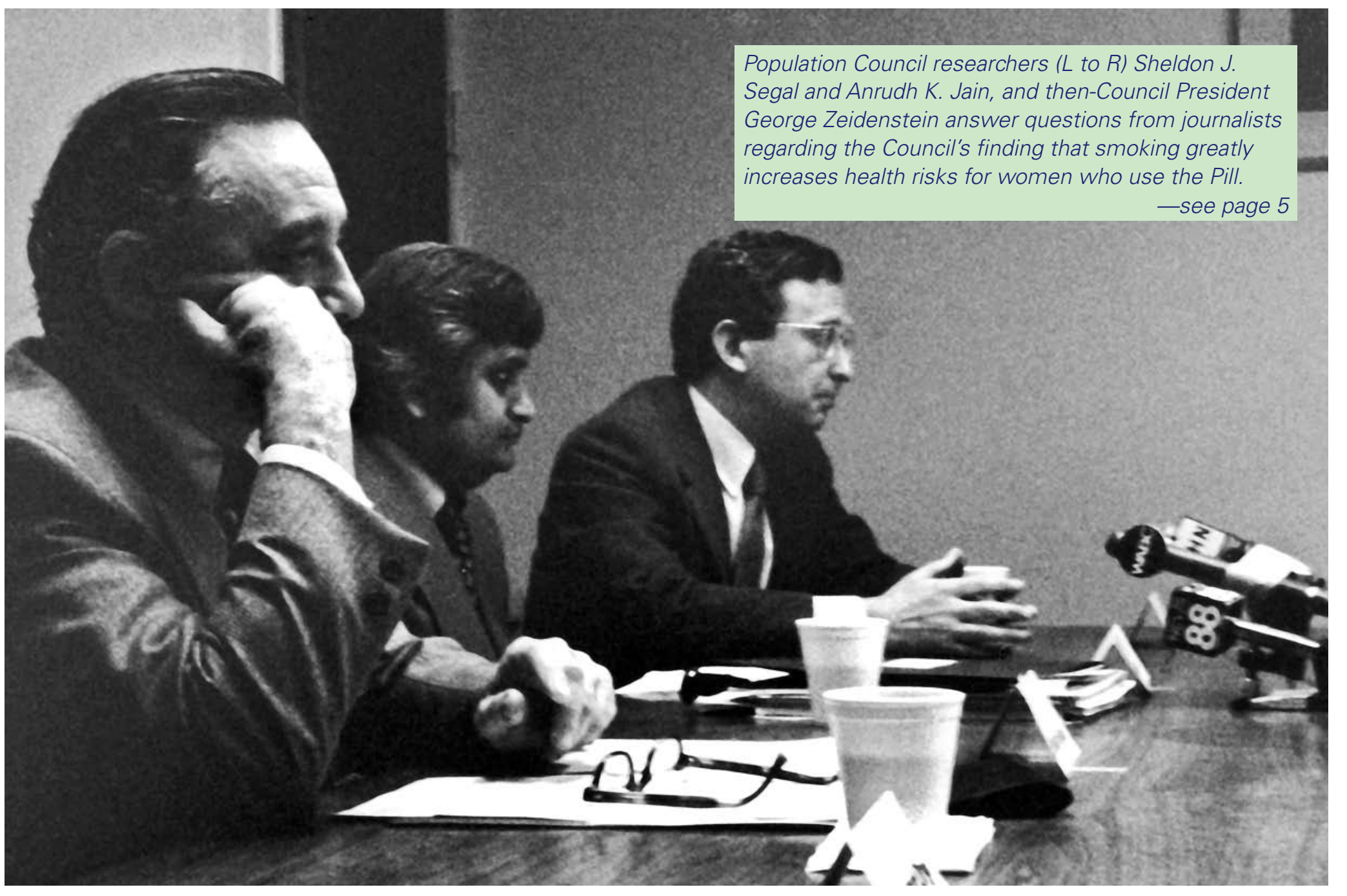

